\title{
EDITORIAL
}

\section{ALGUNAS CONSIDERACIONES SOBRE BUENAS PRÁCTICAS DE COMUNICACIÓN CIENTÍFICA PARA LA U.D.C.A}

\author{
Germán Anzola Montero \\ Rector \\ https://doi.org/10.31910/rudca.v21.n1.2018.656
}

La comunicación es un acto natural donde un individuo establece con otros un contacto, permitiéndole emitir una información. Comunicar, viene del latín communicāre, que significa, entre otras definiciones dadas por la Rae, Hacer a una persona partícipe de lo que se tiene; Descubrir, manifestar o hacer saber a alguien algo, por lo que comunicar una actividad científica -lo que le compete a este editorial-, es un espacio, donde el desarrollo científico, el tecnológico y la innovación, toman la validez requerida; es mostrarle a la sociedad los avances obtenidos por investigadores, por jóvenes investigadores y por semilleros, dando cumplimiento a una obligación inherente a la Misión, a la Visión y a los Principios de la Universidad.

Comunicar científicamente es fortalecer la ciencia, sinónimo de nuevo conocimiento y, para ello, requiere de una compleja red de emisores, de receptores y de canales especializados de transmisión, para avanzar hacia la sociedad del conocimiento, que exige calidad científica e información veraz y oportunidad, como soporte para el progreso social, económico y cultural del país y del mundo.

Con el propósito de aterrizar estas significaciones, justamente, se pensó en crear una normativa institucional, que recoja estrategias específicas, para una coherente y acertada comunicación científica, para aquellos avances de la I+D+I que se generan en la Universidad de Ciencias Aplicadas y Ambientales U.D.C.A y se convierta en un canon para identificar públicos potenciales, espacios de actuación, recursos disponibles, impacto, entre otros.

Se parte de la premisa, que la Universidad cuenta con una norma institucional, que orienta la implementación de los diferentes aspectos de la investigación, que le permiten ver, como una obligación, la creación de conocimiento nuevo, abordado desde una perspectiva sistémica, entendiendo este proceso y sus resultados, como indicador de calidad, cumpliendo, de esta manera, con las expectativas a la delegación hecha por la sociedad a las Universidades, como parte de su misión hacia el desarrollo humano sostenible.
Es así que, desde el PEI, la U.D.C.A define y orienta la actividad investigativa y reafirma sus objetivos y alcances, a través de diferentes políticas y lineamientos para la investigación, en la que se precisa, entre otros, la organización de la investigación, el personal de investigación, los proyectos, la articulación con proyección social, el fomento a la investigación y los apoyos a la formación en investigación, la conformación y participación en redes de investigación. Afianza su postura institucional de visibilizar la producción académica y científica de los profesores, con la promulgación del Acuerdo 454 de 2017, en donde se definen los productos académicos y científicos, la producción según el nivel de formación de los profesores y el procedimiento para el registro y aprobación de los proyectos de investigación. También, se adopta el Acuerdo 454 de 2017 -Presentación y aprobación de proyectos de investigación- y la Resolución 785 de 2018, para la financiación interna de proyectos de investigación, desarrollo tecnológico o innovación.

Además, para garantizar la calidad y la pertinencia de los proyectos de investigación en la Universidad, se reglamentó el Acuerdo 463 de 2018, en el que se define el banco de pares evaluadores, como una instancia interna, que permite cualificar los proyectos de investigación y de desarrollo tecnológico e innovación.

Con base en esta normativa, lo que se pretende con las buenas prácticas de comunicación científica es, justamente, acrecentar y fortificar la cultura de desarrollo tecnológico y de innovación, entre la comunidad universitaria y la científica; concederle la importancia a favor de la sociedad colombiana e internacional y concientizar a la comunidad científica de la U.D.C.A, sobre el afán de difundir y de comunicar los desarrollos en investigación, en innovación y en tecnología.

\section{Formas de comunicación científica}

La Universidad entiende como formas de Comunicación Científica, aquellos medios que un investigador tiene a su disposición para difundir su nuevo conocimiento. Asiduamente, 
se recurre a los escritos para divulgar los resultados de su trabajo (artículos científicos y de desarrollo tecnológico, artículos técnicos o de actualización o de revisión, artículos de reflexiones originales sobre un problema o tópico particular, tesis doctorales y póster) e, igualmente, las presentaciones orales (conferencias, mesas redondas, coloquios). Las reuniones científicas, los simposios o los congresos especializados son otros medios, para que los profesionales de una disciplina, intercambien sus experiencias.

El mecanismo capital para la existencia y la visibilidad de la ciencia está enmarcado en una efectiva y apropiada comunicación científica, definida, en últimas, como el proceso de presentación, de distribución y de recepción de I+D+I, en la sociedad, una nueva forma de comunicar, que debe implementar la investigación universitaria, es decir, una cultura digital, que permite la transformación de algunas formas tradicionales de la comunicación escrita y oral.

Para ello, se dispone de herramientas de comunicación, la mayoría dadas, fundamentalmente, en las nuevas tecnologías de la información y la comunicación (TIC).

Existen canales de comunicación interna, los cuales, están ocupando, un lugar preferente en las Universidades, creados por la necesidad de atender las constantes demandas del quehacer académico, científico y de extensión, cada vez más diverso y exigente. Entre ellos, los de soportes gráfico, como las carteleras institucionales y los de soporte digital, como los mailings, la Intranet y la Web institucional, una de las herramientas más importantes y con mayor futuro para la comunicación científica y de la I+D+I; la creación, la distribución y la arquitectura de sus contenidos también se deben articular con los objetivos de la estrategia de comunicación, que se quiere implementar. Los medios audiovisuales (pantallas de TV internos), también son otro canal de divulgación, reconocidas y aceptadas por los públicos internos; organizar eventos académicos y científicos, permiten conocer el desarrollo científico de la Universidad y abrir la posibilidad de la interdisciplinariedad investigativa; la organización de seminarios, de congresos, de jornadas de investigación, de debates y todo tipo de actividades dirigidas a la comunidad interna y externa, facilitan la dimensión social y la visibilidad de la institución, dar a conocer las actividades que se desarrollan y el conocimiento que se genera en ella. Fomentar los estímulos y los reconocimientos, donde se certifique la labor investigativa de los docentes-investigadores; promover espacios comunes, para el intercambio de conocimiento y el diálogo informal entre los todos los docentes investigadores y estudiantes; editar el Boletín científico, dirigido a la comunidad académica y científica, tanto interna como externa, que legitime la difusión de la investigación científica, de manera dinámica, eficaz e inmediata; crear material informativo dirigido a medios de comunicación, como dos- siers, comunicados y notas de prensa. Los recursos gráfi$\cos y$ audiovisuales permiten la creación de documentos audiovisuales y banco de imágenes de las actividades de investigación que realizan los diferentes grupos de investigación y que sirven para apoyar la relevancia y la dimensión de la investigación, la innovación y el desarrollo científico en la Universidad, como el catálogo corporativo, los trípticos, los folletos y los roll-up's y, consolidar bases especializadas de medios de divulgación científica, con el fin de crear opinión pública, certera y oportuna.

Las herramientas de la comunicación interna, especializadas y abiertas, permite una comunicación bidireccional, es decir, ambas partes emiten información, una de la otra, de manera habitual y formal, con el objetivo de fortalecer la difusión de los acontecimientos académicos y científicos, promovidos por la Universidad.

En este sentido, la comunicación científica interna, pretende lograr un alto grado cualitativo y cuantitativo de percepción, por parte de los públicos internos de la Universidad; mostrarse transparente y objetiva la información que se genere en la Universidad; que la relevancia, la oportunidad y el interés sean las características de los mensajes dirigidos a todos los públicos internos; suscitar un alto interés en los públicos internos y forjar, en el público interno, una buena gestión de comunicación científica externa, logrando ampliar la imagen y la calidad de quehacer académico, científico y de proyección, de la Universidad.

Por otra parte, se puede hablar de comunicación científica externa, que existe por la necesidad por visibilizar la producción académica y la gestión científica de los investigadores y sus grupos, generar datos bibliométricos y reconocimientos a la labor investigativa, adelantada en las Universidades.

La aparición de nuevas herramientas digitales ha supuesto una transformación de la comunicación científica, en todos los ámbitos. Por un lado, la publicación de resultados se ha diversificado, a través de nuevos canales, como las plataformas digitales que implementan las Universidades, las revistas electrónicas de acceso abierto, los repositorios institucionales, las redes sociales y muchos más, ampliando las formas tradicionales de difusión científica. Los videos, los tuits, los posts, los blogs son otras formas de comunicación científica, que se están imponiendo con gran fuerza, permitiendo un contacto ágil y directo entre investigadores y sus comunidades científicas y un mayor acercamiento a la sociedad.

Existen los modelos tradicionales de comunicación científica externa, que permiten la visibilidad necesaria, mas no inmediata, para la producción científica, dando cumplimiento a su fin principal, de difundir los resultados y los procedimientos adelantados. Entre los comunes: la publicación de 
artículos en las diversas tipologías científicas; la producción bibliográfica de alta calidad científica y editorial, como los textos científicos y los capítulos de libro de base investigativa y las comunicaciones o ponencias para eventos especializados. Esta producción siempre busca ser medida, por índices de citas y de impacto, por lo que será necesario cumplir con altos estándares de calidad y someterla a procesos de indización, en bases de datos y en catálogos de bibliotecas. Otra forma de difusión y de visibilidad es la movilidad nacional e internacional de estudiantes y de docentes investigadores y el envío de separatas científicas.

Ahora viene el concepto Web 2.0, que les permite a los investigadores acceder a diversos servicios, como compartir datos, interactuar con mayor facilidad y visibilizar su producción científica. Constituyen la base de esta evolución, las plataformas para la publicación de contenidos, las redes sociales, los servicios como wikis y los portales de alojamiento de fotografías, videos y audios.

Acciones diversas, se pueden pensar en estos espacios digitales y que, desde la Universidad de Ciencias Aplicadas y Ambientales U.D.C.A, se deben empezar a implementar, como: publicar en congresos, en revistas o en editoriales; publicar en el Repositorio Institucional, de Acceso Abierto, tanto propios como compartidos; redactar noticias en blogs, como medio emergente de divulgación de la ciencia y difundir en redes sociales genéricas (las más numerosas y populares), como Facebook, Twitter, Google+Google Plus, Instagram, Tuenti, LinkedIn, Flickr, MySpace o Youtube y en redes académicas y científicas, que permiten una interesante sinergia, mediante interacciones entre sus miembros y que, en la actualidad, tienen un amplio margen de aplicación en las Universidades, por la naturaleza misma de la institución, como generadora de conocimiento.

\section{Protocolo de evaluación de resultados}

Como se pretende crear una normativa de comunicación científica en la U.D.C.A, será necesario establecer un protocolo de monitoreo (evaluación y apreciación), de resultado (que mida tanto los resultados a corto, mediano como a largo plazo) y de impacto, un análisis cualitativo y cuantitativo, que nos permita contar con indicadores de resultados, donde se pueda implementar medidas correctivas, diagnosticar los procesos, identificar públicos potenciales, detectar áreas de actuación, entre otros.

El editorial titulado Algunas consideraciones sobre buenas prácticas de comunicación científica para la U.D.C.A, fue elaborado, de manera conjunta, con la Coordinadora de la Oficina de Publicaciones de la Universidad, Norella Castro Rojas. 